Supporting information

\title{
Kinetic passive sampling: In situ calibration using the contaminant mass measured in parallel samplers with different thicknesses
}

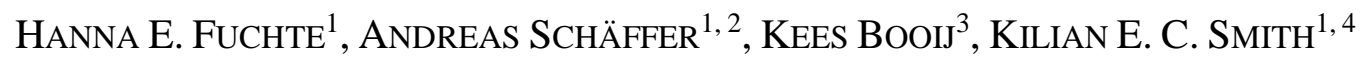 \\ ${ }^{1}$ Institute for Environmental Research, RWTH Aachen University, 52074 Aachen, Germany \\ ${ }^{2}$ State Key Laboratory of Pollution Control and Resource Reuse, School of the Environment, Nanjing 210093, PR \\ China \\ ${ }^{3}$ Passive Sampling of Organic Compounds (PaSOC), Kimswerd, The Netherlands \\ ${ }^{4}$ Current address: Department of Water, Environment, Construction and Safety, University of Applied Sciences \\ Magdeburg-Stendal, 39114 Magdeburg, Germany \\ * Corresponding author e-mail: hanna.fuchte@bio5.rwth-aachen.de
}


Total number of pages: 20; total number of Figures: 11; total number of Tables: 8

\section{Table of contents}

S1 Details and pictures on the experimental set-up

S2 Quality control for laboratory and field study

S3 GC-MS analysis

S4 Derivation of CMR calibration

S5 Estimation of sampling rate for highly hydrophobic substances using the CMR calibration

S6 Experimental data of laboratory study

S7 Experimental data of field study 
S1 Details and pictures on the experimental set-up

Table S1a. Chemical related data.

\begin{tabular}{|l|l|l|}
\hline Chemical & Supplier & Purity (\%) \\
\hline Atrazine & Dr. Ehrenstorfer (Augsburg, Germany) & 99 \\
\hline Hexane & VWR (Darmstadt, Germany) & $>99$ \\
\hline Methanol & VWR (Darmstadt, Germany) & $>99$ \\
\hline Sodium sulfate & VWR (Darmstadt, Germany) & \\
\hline Ultrapure water & Veolia Water (Paris, France) & \\
\hline
\end{tabular}


Table S1b. Literature values of partition coefficients for SSP-M823 silicone (log $\left.K_{S W}\right)$ and those for octanol to water partitioning $\left(\log K_{O W}\right)^{1} . K_{S W}$ values for deuterated and non-deuterated PAHs were taken to be equal. Deuterated PAHs have $\sim 0.05$ lower $\log K_{S W}{ }^{2}$, but that is an insignificant detail in context of the present study.

\begin{tabular}{|c|c|c|c|}
\hline Compound & Abbreviation & $\log K_{s w}[\mathrm{~L} / \mathrm{kg}]$ & $\log$ Kow \\
\hline Acenaphthene $e^{a, b}$ & Ace & 3.43 & 3.97 \\
\hline Acenaphthene-d10 & Ace-d10 & 3.43 & 3.97 \\
\hline Acenaphthylene ${ }^{b}$ & Acy & 3.04 & 3.8 \\
\hline Acenaphthylene-d $8^{b}$ & Acy-d8 & 3.04 & 3.8 \\
\hline Fluorene $^{a, b}$ & Flu & 3.56 & 4.14 \\
\hline Fluorene-d $10^{\mathrm{b}}$ & Flu-d10 & 3.56 & 4.14 \\
\hline Phenanthrene $e^{a, b}$ & Phen & 3.82 & 4.62 \\
\hline Phenanthrene-d $10^{b}$ & Phen-d10 & 3.82 & 4.62 \\
\hline Anthracene $e^{a, b}$ & Anth & 3.91 & 4.73 \\
\hline Anthracene-d $10^{b}$ & Anth-d10 & 3.91 & 4.73 \\
\hline Fluoranthene ${ }^{a, b}$ & Fla & 4.28 & 5.34 \\
\hline Fluoranthene-d $10^{b}$ & Fla-d10 & 4.28 & 5.34 \\
\hline Pyrene $^{\mathrm{a}, \mathrm{b}}$ & Pyr & 4.39 & 5.41 \\
\hline Pyrene-d $10^{\mathrm{b}}$ & Pyr-d10 & 4.39 & 5.41 \\
\hline Benzo[a]anthracene ${ }^{b}$ & $\mathrm{BaA}$ & 4.86 & 5.97 \\
\hline Benzo[a]anthracene-d $12^{\mathrm{b}}$ & BaA-d12 & 4.86 & 5.97 \\
\hline Chrysene $^{\mathrm{b}}$ & Chr & 4.84 & 5.95 \\
\hline Chrysene-d12 ${ }^{\mathrm{b}}$ & Chr-d12 & 4.84 & 5.95 \\
\hline Benzo[b]fluoranthene ${ }^{b}$ & $\mathrm{BbF}$ & 5.33 & 6.5 \\
\hline Benzo[b]fluoranthene- $d 12^{b}$ & BbF-d12 & 5.33 & 6.5 \\
\hline Benzo[k]fluoranthene $e^{a, b}$ & $\mathrm{BkF}$ & 5.29 & 6.63 \\
\hline Benzo[k]fluoranthene- $d 12^{b}$ & BkF-d12 & 5.29 & 6.63 \\
\hline Benzo[a]pyrene $e^{a, b}$ & $\mathrm{BaP}$ & 5.26 & 6.69 \\
\hline Benzo[a]pyrene-d $12^{\mathrm{b}}$ & BaP-d12 & 5.26 & 6.69 \\
\hline Indeno[1,2,3-cd]pyrene ${ }^{b}$ & IndP & 5.6 & 7.23 \\
\hline Indeno[1,2,3-cd]pyrene-d12b & IndP-d12 & 5.6 & 7.23 \\
\hline Dibenzo[a,h]anthracene ${ }^{a, b}$ & DBA & 5.7 & 7.22 \\
\hline Dibenzo[a,h]anthracene-d14 & DBA-d14 & 5.7 & 7.22 \\
\hline Benzo[ghi]perylene $\mathrm{e}^{\mathrm{a}, \mathrm{b}}$ & BghiP & 5.61 & 7.24 \\
\hline Benzo[ghi]perylene-d1 $2^{b}$ & BghiP-d12 & 5.61 & 7.24 \\
\hline
\end{tabular}

${ }^{a}$ used in laboratory study; Sigma-Aldrich (Missouri, USA), purity $>97 \%$

b 16 EPA PAH-MIX and 16 EPA PAH-dx-MIX used in field study; Neochema (Bodenheim, Germany) 

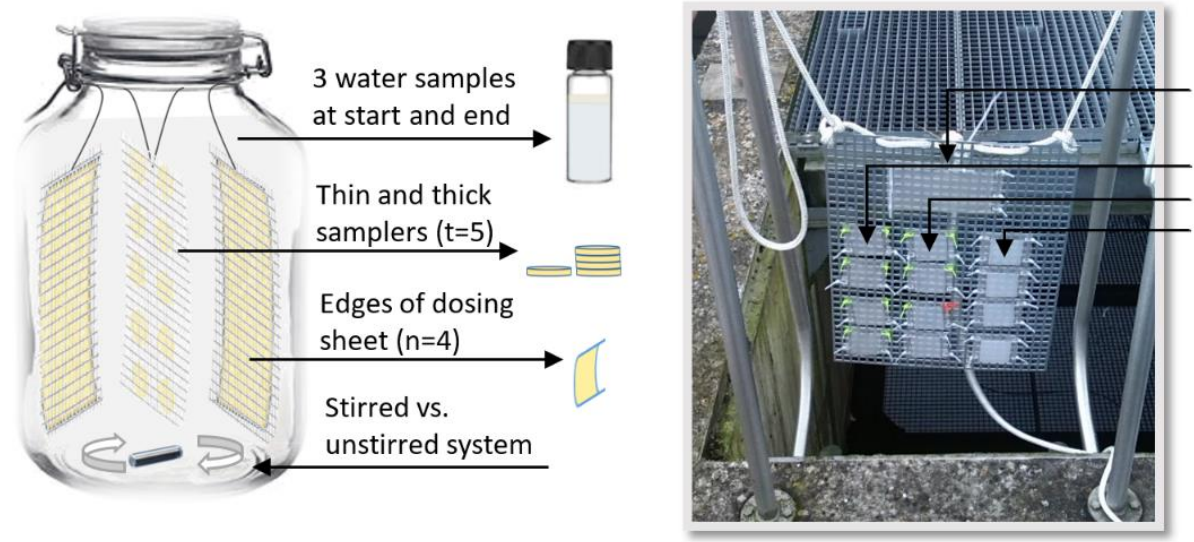

Passive dosing sheet for further experiments

Passive sampler $0.2 \mathrm{~mm}$

Passive sampler $1 \mathrm{~mm}$ Passive sampler $3 \mathrm{~mm}$

Two timepoints (three and six weeks; only first timepoint used in this study), two replicates for each sampler thickness

Figure S1. Experimental set-up of laboratory study (left) and field study (right).

\section{S2 Quality control for laboratory and field study}

For the laboratory study, recoveries from the water extraction were low (13\% for acenaphthene to 90\% for benzo[a]pyrene, see Table S5 for all recovery values), but always reproducible (rsd 1-9.3\%) and therefore used for recovery correction. These were used to control constancy of the water concentrations during the experiment. Constant water concentrations were in fact observed, as indicated by the similar mean PAH concentrations for the majority of compounds. Ratios between mean concentrations for start and end ranged between 1.2 and 2.3. Exceptions were dibenzo[a,h]anthracene and benzo[ghi]perylene, where equilibrium between the dosing and water phases was likely not fully attained for both substances. Water concentrations for these compounds were lower than expected in the unstirred system $(<100 \mathrm{ng} / \mathrm{L})$, and continually increased in the stirred system (from 50 to $157 \mathrm{ng} / \mathrm{L}$ for dibenzo[a,h]anthracene and 34 to $174 \mathrm{ng} / \mathrm{L}$ for benzo[ghi]perylene). Homogeneity of the PAH loading process for the passive dosing sheets was evident from the low rsd between the sub-samples which were all between 11 and 24\%. No PAHs were detected in the solvent blanks, and only fluoranthene and pyrene were found in the sampler fabrication blanks. These comprised 49 and $26 \%$, respectively, of the amounts detected in the samplers collected at the very first timepoint, which had the lowest accumulated amounts. However, these blank levels were much less than the sampler-accumulated amounts for the later timepoints. The three sampler fabrication blanks had reproducible fluoranthene and pyrene levels, and the sampler extracts have been blank-corrected. For the field study, recoveries were calculated from PRC-spiked solvent samples run through the same extraction and solvent-concentration process as used for the passive samplers. Recoveries were between $53 \%$ for indeno[1,2,3-cd]pyrene-d12 to $89 \%$ for benzo[a]anthracene-d12, and were also reproducible with rsd between $6 \%$ for pyrene-d 10 and $22 \%$ for indeno[1,2,3-cd]pyrene-d12. Similar PAH concentrations accumulated in the three sheets pressed together to make the thickest passive sampler. The rsd between the three sheets ranged from $0.2 \%$ (chrysene, site 3) to $36 \%$ (phenanthrene, site 2). This shows that the internal mass transfer was fast and that these can be considered a homogenous sampling phase. The field blanks contained less than $1 \mathrm{ng} / \mathrm{sample}$ for the individual 
PAHs, with the exception of naphthalene where the amounts were $2.8 \mathrm{ng} / \mathrm{sample}$. These naphthalene concentrations were in the same range as measured in the recovered samplers, and this compound has therefore been excluded from the discussion. For the remaining PAHs, the blank concentrations were $<1 \%$ of the amounts detected in any of the field-deployed samplers, with exception of phenanthrene where the blanks made $<8 \%$ of the accumulated amounts. In view of these small amounts, the passive sampling results have not been blank corrected. PRC losses due to photodegradation or other processes were low as shown by the quantitative recoveries of those heavier PAHs that are susceptible to this loss pathway (e.g., benzo[a]anthracene $)^{3}$. Low photodegradation is likely due to a high turbidity of the surface runoff leading to scattering and absorption of the light.

\section{S3 GC-MS analysis}

For the PAH analysis, an Agilent7890 A GC system with 5975 C inert XL MSD was used. The carrier gas was helium (5.0, Praxair, Connecticut, USA). A volume of $1 \mu \mathrm{L}$ was injected in splitless mode. The PAHs were separated on an Agilent HP-5 ms column ( $30 \mathrm{~m} \times 0.25 \mathrm{~mm}, 0.25 \mu \mathrm{m}$, California, USA). The inlet and transfer line were both kept at $290^{\circ} \mathrm{C}$ and the electron (ion) source and quadrupole at 150 and $240{ }^{\circ} \mathrm{C}$, respectively. The flow rate was set to $1.5 \mathrm{~mL} / \mathrm{min}$. The oven temperature program was as follows: Starting temperature of $70{ }^{\circ} \mathrm{C}$ held for $1 \mathrm{~min}$, increase to $320^{\circ} \mathrm{C}$ during $10 \mathrm{~min}$ (heating rate of $25^{\circ} \mathrm{C} / \mathrm{min}$ ), $320^{\circ} \mathrm{C}$ held for $5 \mathrm{~min}$. MSD was used in SIM mode with 2 to 3 masses monitored for each compound. Quantification was done by confirmation of retention times and looking at the ratios of the mass fragments monitored in the SIM method. The most abundant mass was used for quantification, and one to two additional masses with high intensities were used as qualifiers.

\section{S4 Derivation of CMR calibration}

Preliminary note: In the M\&M theory section, special attention was paid to the accumulating contaminant mass in the sampler $\left(N_{S, \text { thin }}\right.$ vs. $\left.N_{S, \text { thick }}\right)$. The aim was to highlight that these are the values, which are produced during GC analysis and which must be analytically distinguishable in order to reliably determine the dissolved concentrations. Since passive sampler accumulation is often described in terms of concentrations, the derivation below is described in terms of sampler concentrations rather than amounts. Of course, for all equations, these can easily be converted into accumulated amounts by multiplying with the sampler volume $\left(C_{W} V_{S}\right)$.

Experimental concept: When passive samplers with identical surface areas but different volumes (e.g., disks of different thicknesses) are deployed in parallel, then the temporal evolution in the sampler concentrations are different as in Figure S2 showing the fitted experimental data of acenaphthene in the stirred system. Thus, the ratio of the two sampler concentrations versus time continually decreases until it approaches 1 . When this ratio is 1 , then both samplers are at a thermodynamic equilibrium with the surrounding aqueous medium and thus have the same concentrations. 


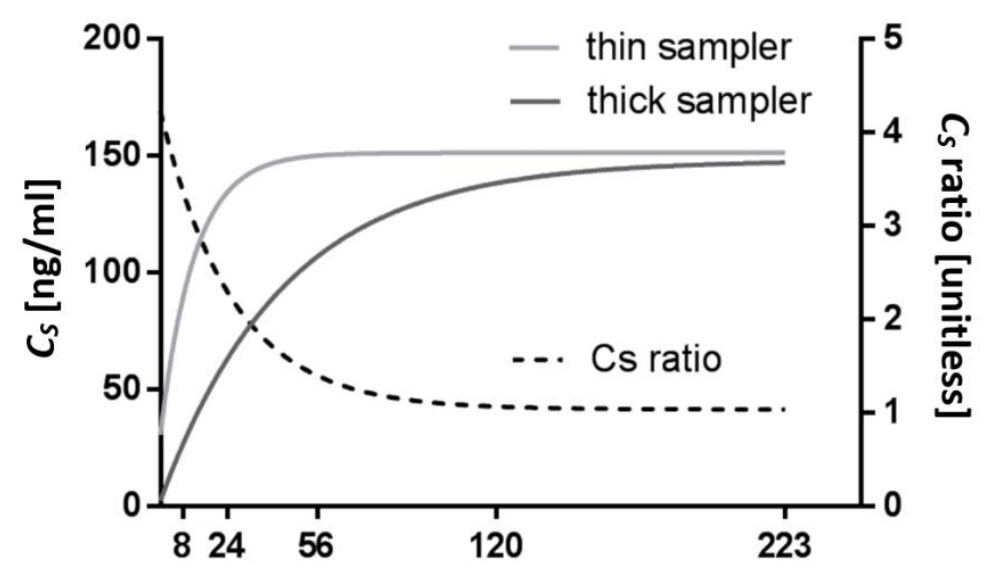

Figure S2. Change in acenaphthene concentrations over time for parallel samplers with the same surface area but different volumes (volume ratio=4). The black dotted line gives the sampler concentration ratio.

Calculations: Uptake by a passive sampler can be described by the following equation:

$$
C_{S}=C_{W} K_{S W}\left(1-\exp \left[-k_{e} t\right]\right)
$$

Where $C_{S}$ is the passive sampler concentration $\left(\mathrm{ng} / \mathrm{cm}^{3}\right), C_{W}$ is the external dissolved concentration $\left(\mathrm{ng} / \mathrm{cm}^{3}\right), K_{S W}$ is the equilibrium sampler to water partition coefficient $\left(\mathrm{cm}^{3} / \mathrm{cm}^{3}\right), k_{e}$ is the elimination rate constant $(1 / \mathrm{h})$ and $t$ is time $(\mathrm{h})$.

When solving for the elimination rate constant $\left(k_{e}\right)$ this is:

$$
-k_{e}=\frac{\ln \left(1-\frac{C_{S}}{C_{W} K_{S W}}\right)}{t}
$$

$k_{e}$ is also given by:

$$
k_{e}=\frac{k_{o} A_{S}}{K_{S W} V_{S}}
$$

Where $k_{o}$ is the mass-transfer coefficient $(\mathrm{cm} / \mathrm{h}), A_{S}$ is the sampler surface area in contact with the external medium $\left(\mathrm{cm}^{2}\right)$ and $V_{S}$ is the volume of the sampler $\left(\mathrm{cm}^{3}\right)$. The product $\left(k_{0} A_{S}\right)$ is the apparent water sampling rate $R_{S}\left(\mathrm{~cm}^{3} / \mathrm{h}\right)$.

When the samplers are deployed in parallel then from Equation S3 it follows that:

$$
\frac{k_{e, \text { thin }}}{k_{e, \text { thick }}}=\frac{\frac{k_{o, \text { thin }} A_{S, \text { thin }}}{K_{S W, \text { thin }} V_{S, \text { thin }}}}{\frac{k_{o, \text { thick }} A_{S, \text { thick }}}{K_{S W, \text { thick }} V_{S, \text { thick }}}}
$$

Since the samplers are of the same material, have the same architectures and experience the same hydrodynamic conditions, they have the same mass transfer coefficients (i.e., $k_{o, \text { thin }}=k_{o, \text { thick }}$ ), surface areas (i.e., $A_{S, \text { thin }}=A_{S, \text { thick }}$ ) and sampler:water partition coefficients (i.e., $K_{S W, \text { thin }}=K_{S W, \text { thick }}$ ). Equation S4 
thus reduces to Equation S5. (Distribution coefficient and surface area do not necessarily have to be the same for both samplers. As long as these are known, they could be included in the equation, which makes application of the approach more flexible.)

$$
\frac{k_{e, \text { thin }}}{k_{e, \text { thick }}}=\frac{V_{S, \text { thick }}}{V_{S, \text { thin }}}
$$

After combining Equation S2 for thin and thick sampler and Equation S5, this becomes:

$$
\frac{\ln \left(1-\frac{\mathrm{C}_{\mathrm{S}, \text { thin }}}{\mathrm{C}_{\mathrm{W}} \mathrm{K}_{\mathrm{SW} \text {,thin }}}\right)}{\mathrm{t}}=\frac{\mathrm{V}_{\mathrm{S} \text {,thick }}}{\mathrm{V}_{\mathrm{S} \text {,thin }}} \frac{\ln \left(1-\frac{\mathrm{C}_{\mathrm{S} \text {,thick }}}{\mathrm{C}_{\mathrm{W}} \mathrm{K}_{\mathrm{SW} \text {,thick }}}\right)}{\mathrm{t}}
$$

and after rearranging Equation S6 we have (this is the same as Equation 2 in the main text):

$$
\left(1-\frac{C_{S, \text { thin }}}{C_{W} K_{S W, \text { thin }}}\right)^{V_{S, \text { thin }}}=\left(1-\frac{C_{S, \text { thick }}}{C_{W} K_{S W, \text { thick }}}\right)^{V_{S, \text { thick }}}
$$

Thus an expression is formed, relating the sampler kinetics of the two samplers with different thicknesses, in which the only unknown is $C_{W}$, the dissolved concentration that is to be determined. At equilibrium Equation $\mathrm{S} 7$ collapses to $0=0$ and $C_{W}$ can be calculated using the partition coefficient and the concentration in e.g. the thinner sampler. In this case, the thicker sampler only serves to indicate equilibrium by showing the same sampler concentration.

Equation S7 can be solved graphically or numerically. For the graphical solution the two measured concentrations in the field deployed samplers $\left(C_{S, \text { thin }}\right.$ and $\left.C_{S, \text { thick }}\right)$ are used together with the known sampler characteristics to solve the left and right hand side of Equation $\mathrm{S} 7$ for different values of $C_{W}$. Two lines, representing the left and right hand sides of Equation S7, are plotted against this range of $C_{W}$ values and only cross, i.e., have the same solution, when the tested $C_{W}$ value conforms with the real dissolved concentration. For the numerical solution Equation S7 can be rearranged to Equation S8 below. The value of $C_{W}$ that satisfies Equation $\mathrm{S} 8$ can then be found out using any numerical solution tool, for example, the Excel solver tool.

$$
\left(1-\frac{C_{S, \text { thin }}}{C_{W} K_{S W, \text { thin }}}\right)-\left(1-\frac{C_{S, \text { thick }}}{C_{W} K_{S W, \text { thick }}}\right)^{\frac{V_{S, \text { thick }}}{V_{\text {,thin }}}}=0
$$

Error analysis: When the accumulated amounts in the thin and thick samplers are too similar (due to both still being in the linear stage of uptake), then measurement errors can overestimate accumulation in the thinner sampler or underestimate accumulation in the thicker sampler such that the numerical solution is then incorrect. Model simulations in Excel show that with a representative measurement error of $5 \%$, the thin sampler must have reached approximately $40 \%$ of its equilibrium level to robustly determine $C_{W}$ based on the above considerations. Equilibrium attainment is below specified as $C_{S,} /\left(K_{S W} C_{W}\right)$, the fraction of equilibrium $\left(f_{e q}\right)$. 
Ten simulations were made, assuming a system described by the following parameters:

$\begin{array}{ll}k_{o} & 100 \mathrm{~cm} / \mathrm{h} \\ A_{S} & 1 \mathrm{~cm}^{2} \\ R_{S} & 100 \mathrm{~cm}^{3} / \mathrm{h} \\ K_{S W} & 1000 \mathrm{~cm}^{3} / \mathrm{cm}^{3} \\ C_{W} & 1 \mathrm{ng} / \mathrm{cm}^{3} \text { (target dissolved concentration in the surrounding medium) } \\ V_{S, \text { thin }} & 1 \mathrm{~cm}^{3} \\ V_{S, \text { thick }} & 10 \mathrm{~cm}^{3}\end{array}$

From these parameters $N_{S, \text { thin }}$ and $N_{S, \text { thick }}$ were calculated and $5 \%$ random normal noise was added to the values. These were then converted into $C_{S \text {, thin }}$ and $C_{S \text {,thick }}$ by dividing by the sampler volume $\left(N_{S} / V_{S}\right)$. Applying Equation S8 (Eq. 2) resulted in $C_{W}$ values of $1.13+/-0.27 \mathrm{ng} / \mathrm{cm}^{3}$ (see Table S2). Thus a measurement error of 5\% led to a relative standard deviation of $24 \%$. When $f_{e q}$ was less than $40 \%$ for the thinner sampler then by chance the measurement errors resulted in instances with an incorrect reversed amount ratio and thus an incorrect solution. For these cases the CMR calibration has to be enhanced as described in S5.

Table S2. Ten simulations of $C_{W}$ calculation at $t=5 \mathrm{~h}$ and $f_{\text {eq thin }}=0.4$ using Equation S8 (Eq. 2).

\begin{tabular}{|c|c|c|c|c|c|c|}
\hline & $C_{S, \text { thin }}$ & $C_{\text {s,thick }}$ & $N_{s, \text { thin }}$ & $N_{\text {s, thick }}$ & $C_{w}$ & $C_{S, \text { thin }} / C_{S \text {, thick }}$ \\
\hline & {$\left[\mathrm{ng} / \mathrm{cm}^{3}\right]$} & {$\left[\mathrm{ng} / \mathrm{cm}^{3}\right]$} & [ng] & [ng] & {$\left[\mathrm{ng} / \mathrm{cm}^{3}\right]$} & - \\
\hline exact value & 393 & 49 & 393 & 488 & 1.00 & 8.07 \\
\hline simulation 1 & 405 & 50 & 405 & 500 & 1.04 & 8.10 \\
\hline simulation 2 & 396 & 49 & 396 & 489 & 1.01 & 8.09 \\
\hline simulation 3 & 376 & 46 & 376 & 461 & 0.99 & 8.14 \\
\hline simulation 4 & 404 & 46 & 404 & 459 & 1.58 & 8.79 \\
\hline simulation 5 & 367 & 44 & 367 & 437 & 1.11 & 8.41 \\
\hline simulation 6 & 423 & 49 & 423 & 494 & 1.41 & 8.56 \\
\hline simulation 7 & 408 & 51 & 408 & 512 & 0.99 & 7.96 \\
\hline simulation 8 & 376 & 47 & 376 & 468 & 0.94 & 8.03 \\
\hline simulation 9 & 412 & 47 & 412 & 473 & 1.52 & 8.71 \\
\hline simulation 10 & 380 & 51 & 380 & 511 & 0.75 & 7.44 \\
\hline
\end{tabular}




\section{S5 Estimation of sampling rate for highly hydrophobic substances using the CMR}

calibration

When substances remain in the early linear stage of uptake during sampler deployment, it is not possible to analytically distinguish the small differences in accumulated amounts between a thin and thick sampler. In practice, this applies to those compounds with a high sampler-water partition coefficient ( $\log K_{S W}>4.4$ in this study). For the PRC-approach, the analogous problem is the limited dissipation of the heavier compounds, which makes it difficult to reliably distinguish a decrease from the starting PRC concentrations. For the PRC-approach, Booij and Smedes (2010) showed that this issue can be overcome by modeling sampling rates using the complete PRC dataset, including those compounds with either full or limited dissipation. Here, the $R_{S}$ of a compound can be calculated using a proportionality constant $B$, which reflects exposure-specific effects (e.g. temperature and flow) and the sampler area but does not depend on the molecular weight $(M)$ and is thus assumed to be independent of the compound properties. $B$ can be determined by fitting all PRC fractions as a function of $K_{S W} M^{0.47}$ using unweighted non-linear least-squares and is relatively insensitive to outliers. In this way, all PRC dissipation data can be used, irrespective of their degree of dissipation. ${ }^{4}$

For the CMR calibration information describing the deployment-specific uptake kinetics using the complete data set can be obtained in an analogous manner by applying Equation 3 in the main text. As long as some compounds have reached a certain stage of equilibrium, $B$ can be determined using nonlinear least-squares regression and this subsequently serves to estimate the specific sampling rates for all substances, taking into account their molecular weights. This extends the range of application to the more hydrophobic compounds that remain in the linear uptake regime. An example is given in Figure S3, showing the contaminant mass ratio plot for the stirred system (last timepoint). An exemplary sampling rate for a compound with a molar mass of $300 \mathrm{~g} / \mathrm{mol}$ was determined from $\mathrm{B}$ and is shown in the graph together with its associated uncertainty.

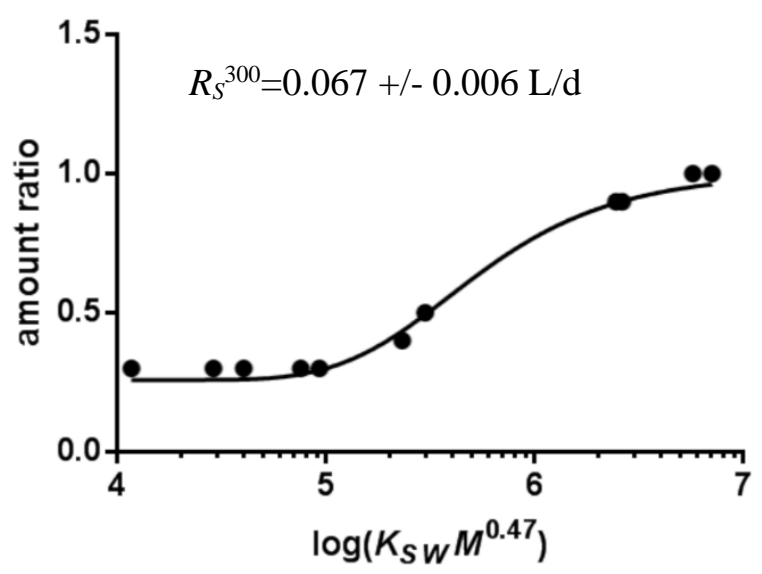

Figure S3. Contaminant mass ratio plot to determine $B$ and estimate $R_{S}$ in the stirred system (last timepoint).

For the light to intermediate substances, where a sufficient degree of equilibrium is usually attained, two ways of $C_{W}$ calculation are thus possible. First, the direct calculation using the individual ratio of 
the substance amounts in thin and thick samplers (Eq. 2). Second, via the estimation of a common B analogous to the PRC-approach (Eq. 3). In this study, the individual determination of $C_{W}$ using Equation 2 was applied to acenaphthene to pyrene in the lab experiment and acenaphthylene to anthracene in the field experiment. In any case, for the PAHs calculated using the individual amount ratios and Equation 2, modeling the uptake using Equation 3 led to similar results as shown in Table S3. This underlines that the estimation via B (Eq. 3), which was done for the higher MW PAHs in this study, can always be applied since it is based on the amount ratios for the full range of compounds (analogous to the way that the full range of PRCs are used).

Table S3. Comparison of $C_{W-C M R}$ values* for light PAHs in the stirred system, derived individually using Equation 2 vs. modeled using Equation 3.

\begin{tabular}{|l|l|l|l|}
\hline & CW-CMR eq. & $C_{W \text {-CMR thin eq. 3 }}$ & $\begin{array}{l}\text { CW-CMR thick eq. 3 } \\
{[\mathrm{ng} / \mathrm{L}]}\end{array}$ \\
\hline [ng/L] & {$[\mathrm{ng} / \mathrm{L}]$} & $74 \pm 2$ \\
\hline Acenaphthene & $76 \pm 2$ & $76 \pm 2$ & $157 \pm 9$ \\
\hline Fluorene & $153 \pm 17$ & $154 \pm 13$ & $165 \pm 11$ \\
\hline Phenanthrene & $141 \pm 21$ & $151 \pm 9$ & $134 \pm 15$ \\
\hline Anthracene & $122 \pm 25$ & $131 \pm 11$ & $125 \pm 18$ \\
\hline Fluoranthene & $93 \pm 19$ & $111 \pm 5$ & $331 \pm 52$ \\
\hline
\end{tabular}

*mean of all timepoints, where equilibrium attainment was higher than $40 \%$ in the thin sampler. 


\section{S6 Experimental data of laboratory study}

Table S4. PAH concentrations in $1 \mathrm{~cm}^{2}$ pieces removed from the corner of each dosing sheet $\left(C_{D S}\right)$ in the stirred and unstirred laboratory system.

\begin{tabular}{|c|c|c|c|c|c|c|c|c|c|c|}
\hline & CDS 1 & CDS 2 & $\operatorname{CDS} 3$ & $\operatorname{CDS} 4$ & $\operatorname{CDS} 5$ & $\operatorname{Cos} 6$ & CDS 7 & CDS 8 & CDS mean & rsd \\
\hline & {$[\mathrm{mg} / \mathrm{kg}]$} & {$[\mathrm{mg} / \mathrm{kg}]$} & {$[\mathrm{mg} / \mathrm{kg}]$} & {$[\mathrm{mg} / \mathrm{kg}]$} & {$[\mathrm{mg} / \mathrm{kg}]$} & {$[\mathrm{mg} / \mathrm{kg}]$} & {$[\mathrm{mg} / \mathrm{kg}]$} & {$[\mathrm{mg} / \mathrm{kg}]$} & {$[\mathrm{mg} / \mathrm{kg}]$} & [\%] \\
\hline Acenaphthene & 0.1 & 0.1 & 0.1 & 0.1 & 0.1 & 0.1 & 0.1 & 0.1 & 0.1 & 13 \\
\hline Fluorene & 0.3 & 0.4 & 0.4 & 0.3 & 0.3 & 0.3 & 0.3 & 0.3 & 0.3 & 19 \\
\hline Phenanthrene & 0.6 & 0.8 & 0.8 & 0.6 & 0.7 & 0.6 & 0.7 & 0.7 & 0.7 & 12 \\
\hline Anthracene & 0.7 & 0.8 & 0.9 & 0.6 & 0.8 & 0.6 & 0.7 & 0.7 & 0.7 & 12 \\
\hline Fluoranthene & 1.6 & 1.7 & 1.7 & 1.4 & 1.4 & 1.2 & 1.9 & 1.5 & 1.6 & 14 \\
\hline Pyrene & 5.0 & 5.5 & 5.6 & 4.5 & 4.7 & 4.0 & 6.0 & 4.9 & 5.0 & 13 \\
\hline Benzo[k]fluoranthene & 108 & 98 & 103 & 89 & 90 & 80 & 108 & 90 & 96 & 11 \\
\hline Benzo[a]pyrene & 61 & 56 & 58 & 52 & 51 & 46 & 63 & 50 & 55 & 11 \\
\hline Dibenzo[a,h]anthracene & 515 & 313 & 315 & 297 & 453 & 317 & 305 & 284 & 350 & 24 \\
\hline Benzo[ghi]perylene & 268 & 201 & 182 & 211 & 208 & 180 & 249 & 182 & 210 & 16 \\
\hline
\end{tabular}

$C_{D S}: P A H$ concentration in dosing sheet in $\mathrm{mg} / \mathrm{kg}$

rsd: relative standard deviation in \% 
Table S5. Mean water concentrations $\left(C_{W-e x t r .}\right)$ in the stirred and unstirred laboratory system and recovery of the water extraction method in $\%$.

\begin{tabular}{|c|c|c|c|c|c|c|c|c|c|c|}
\hline & \multicolumn{2}{|c|}{ unstirred start } & \multicolumn{2}{|c|}{ unstirred end } & \multicolumn{2}{|c|}{ stirred $_{\text {start }}$} & \multicolumn{2}{|c|}{ stirred end } & \multicolumn{2}{|c|}{ recovery } \\
\hline & $C_{W \text {-extr. }}$ & rsd & $C_{W \text {-extr. }}$ & rsd & $C_{W \text {-extr. }}$ & rsd & $C_{W \text {-extr. }}$ & rsd & rec. & rsd \\
\hline & {$[\mathrm{ng} / \mathrm{mL}]$} & [\%] & {$[\mathrm{ng} / \mathrm{mL}]$} & [\%] & {$[\mathrm{ng} / \mathrm{mL}]$} & [\%] & {$[\mathrm{ng} / \mathrm{mL}]$} & [\%] & [\%] & {$[\%]$} \\
\hline Acenaphthene & 0.16 & 8 & 0.13 & 7 & 0.12 & 9 & $0.16 *$ & 3 & 13 & 6 \\
\hline Fluorene & 0.13 & 8 & 0.09 & 21 & 0.08 & 32 & $0.14 *$ & 18 & 17 & 9 \\
\hline Phenanthrene & 0.13 & 6 & 0.10 & 15 & 0.09 & 18 & $0.14 *$ & 13 & 24 & 2 \\
\hline Anthracene & 0.10 & 6 & 0.07 & 21 & 0.07 & 22 & $0.11 *$ & 11 & 25 & 6 \\
\hline Fluoranthene & 0.09 & 3 & 0.07 & 19 & 0.07 & 23 & $0.11 *$ & 5 & 29 & 9 \\
\hline Pyrene & 0.25 & 5 & 0.19 & 19 & 0.21 & 28 & $0.29 *$ & 3 & 30 & 9 \\
\hline Benzo[k]fluoranthene & 0.49 & 4 & 0.30 & 20 & 0.30 & 19 & $0.60^{*}$ & 11 & 68 & 7 \\
\hline Benzo[a]pyrene & 0.22 & 3 & 0.12 & 59 & 0.14 & 16 & $0.31 *$ & 3 & 90 & 7 \\
\hline Dibenzo[a,h]anthracene & $0.09 *$ & 15 & 0.04 & 38 & 0.05 & 66 & $0.16^{*}$ & 17 & 87 & 5 \\
\hline Benzo[ghi]perylene & $0.09 *$ & 12 & 0.04 & 43 & 0.03 & 37 & $0.17 *$ & 24 & 58 & 7 \\
\hline
\end{tabular}

rsd: relative standard deviation; rec.: recovered

* based on two instead of three replicate values

Table S6a. Elimination $\left(k_{e}\right)$ and sampling $\left(R_{S p l o t}\right)$ rates in the stirred laboratory system for the thin $(0.2 \mathrm{~mm})$ and thick $(4 \times 0.2 \mathrm{~mm})$ sheets. The sampling rates modeled using Equation 3 are also shown $\left(R_{\text {Seq. } 3) \text {. }}\right.$

\begin{tabular}{|c|c|c|c|c|c|}
\hline & $k_{e, t h i n}$ & $k_{e, \text { thick }}$ & $R_{\text {s,thin plot }}$ & $R_{\text {s,thick plot }}$ & $R_{\text {seq. } 3}$ \\
\hline & {$[1 / d]$} & {$[1 / d]$} & {$[\mathrm{L} / \mathrm{d}]$} & {$[L / d]$} & {$[L / d]$} \\
\hline Acenaphthene & $2.57 \mathrm{E}+00$ & $5.58 \mathrm{E}-01$ & 0.080 & 0.070 & 0.085 \\
\hline Fluorene & $1.45 \mathrm{E}+00$ & $4.52 \mathrm{E}-01$ & 0.061 & 0.076 & 0.082 \\
\hline Phenanthrene & $9.84 \mathrm{E}-01$ & $2.36 \mathrm{E}-01$ & 0.075 & 0.072 & 0.079 \\
\hline Anthracene & $6.91 \mathrm{E}-01$ & $2.27 \mathrm{E}-01$ & 0.065 & 0.086 & 0.079 \\
\hline Fluoranthene & 2.57E-01 & $5.35 \mathrm{E}-02$ & 0.057 & 0.047 & 0.075 \\
\hline Pyrene & $2.08 \mathrm{E}-01$ & $5.04 \mathrm{E}-02$ & 0.059 & 0.057 & 0.075 \\
\hline Benzo[k]fluoranthene & $1.75 \mathrm{E}-02$ & $5.02 \mathrm{E}-03$ & 0.039 & 0.045 & 0.067 \\
\hline Benzo[a]pyrene & $1.23 \mathrm{E}-02$ & 3.31E-03 & 0.026 & 0.028 & 0.067 \\
\hline Dibenzo[a,h]anthracene & $9.81 \mathrm{E}-04$ & 2.71E-04 & 0.006 & 0.006 & 0.064 \\
\hline Benzo[ghi]perylene & $9.72 \mathrm{E}-04$ & 2.17E-04 & 0.005 & 0.004 & 0.065 \\
\hline
\end{tabular}

plot: derived via curve fitting 
Table S6b. Elimination $\left(k_{e}\right)$ and sampling $\left(R_{S p l o t}\right)$ rates in the unstirred laboratory system for the thin and thick sheets. The sampling rates modeled using Equation 3 are also shown $\left(R_{S \text { eq. }}\right)$.

\begin{tabular}{|l|l|l|l|l|l|}
\hline & $k_{e, \text { thin }}$ & $k_{\text {e,thick }}$ & $R_{\text {s,thin plot }}$ & $R_{\text {s,thick plot }}$ & $R_{\text {s eq. } 3}$ \\
\hline Acenaphthene & {$[1 / \mathrm{d}]$} & {$[1 / \mathrm{d}]$} & {$[\mathrm{L} / \mathrm{d}]$} & {$[\mathrm{L} / \mathrm{d}]$} & {$[\mathrm{L} / \mathrm{d}]$} \\
\hline Fluorene & $2.26 \mathrm{E}-01$ & $5.97 \mathrm{E}-02$ & 0.007 & 0.007 & 0.014 \\
\hline Phenanthrene & $1.60 \mathrm{E}-01$ & $3.57 \mathrm{E}-02$ & 0.007 & 0.006 & 0.014 \\
\hline Anthracene & $1.20 \mathrm{E}-01$ & $3.26 \mathrm{E}-02$ & 0.009 & 0.010 & 0.013 \\
\hline Fluoranthene & $3.98 \mathrm{E}-02$ & $1.74 \mathrm{E}-02$ & 0.004 & 0.007 & 0.013 \\
\hline Pyrene & $1.64 \mathrm{E}-02$ & $6.05 \mathrm{E}-03$ & 0.004 & 0.005 & 0.013 \\
\hline Benzo[k]fluoranthene & $1.34 \mathrm{E}-02$ & $4.69 \mathrm{E}-03$ & 0.004 & 0.005 & 0.013 \\
\hline Benzo[a]pyrene & $6.52 \mathrm{E}-04$ & $2.45 \mathrm{E}-04$ & 0.001 & 0.002 & 0.011 \\
\hline Dibenzo[a,h]anthracene & $\mathrm{n} / \mathrm{a}$ & $\mathrm{n} / \mathrm{a}$ & $\mathrm{n} / \mathrm{a}$ & $\mathrm{n} / \mathrm{a}$ & 0.011 \\
\hline Benzo[ghi]perylene & $\mathrm{n} / \mathrm{a}$ & $\mathrm{n} / \mathrm{a}$ & $\mathrm{n} / \mathrm{a}$ & $\mathrm{n} / \mathrm{a}$ & 0.011 \\
\hline
\end{tabular}

plot: derived via curve fitting

n/a: no $R_{S}$ available, due to PAH amounts below the limit of quantification 


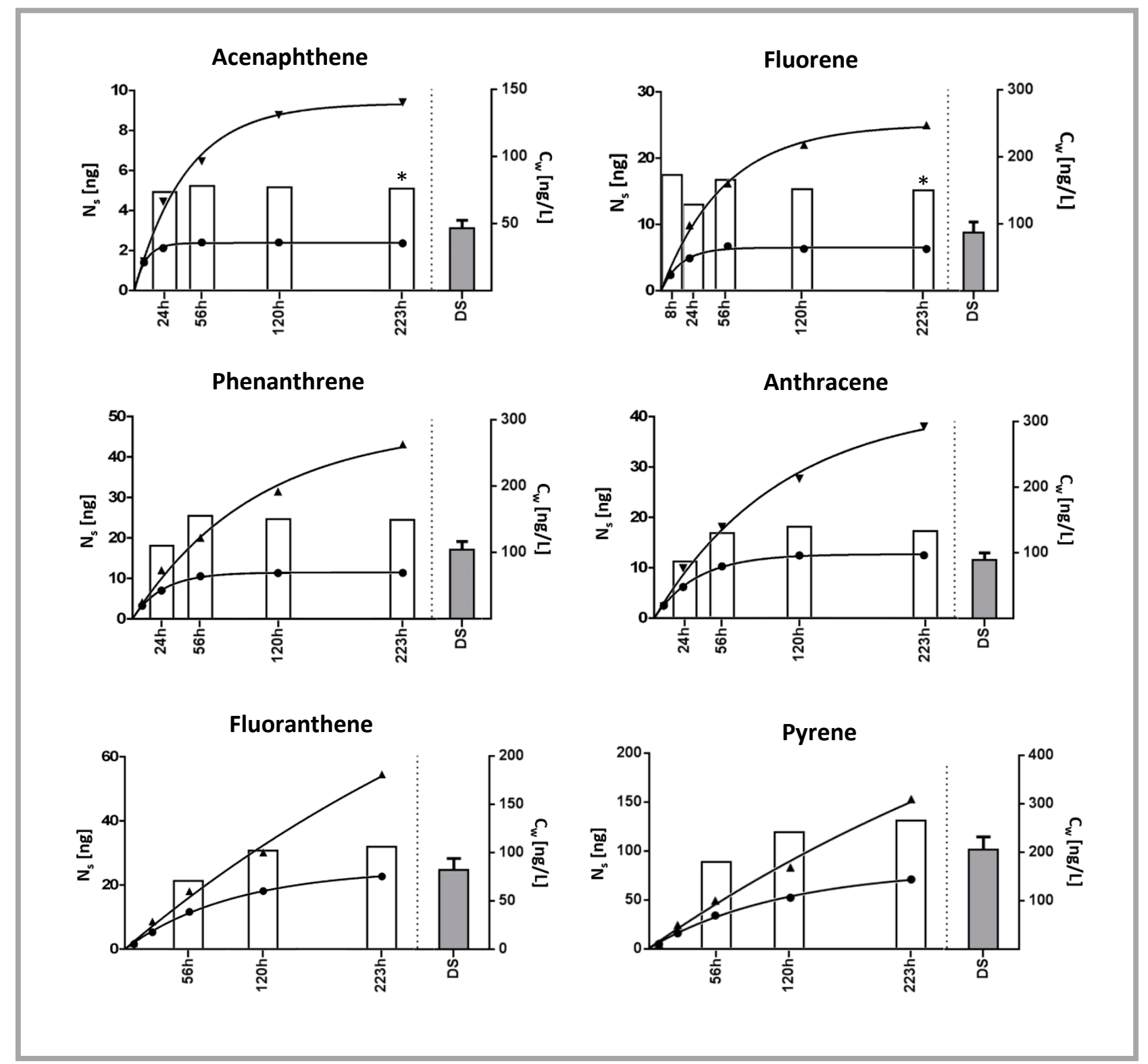

Figure S4. Uptake curves for PAHs and dissolved concentrations $\left(C_{W}, n g / L\right)$ calculated for those timepoints with more than $40 \%$ equilibrium attainment via the CMR calibration or when sampler equilibrium was reached for both samplers via the equilibrium partition coefficient (*). Circles indicate the accumulated PAH amounts in the thin sampler and triangles indicate the accumulated PAH amounts in the thick sampler $\left(N_{S}, n g\right)$. 




Figure S5. Uptake curves for PAHs with less than $40 \%$ equilibrium attainment in the stirred system. Circles indicate the accumulated PAH amounts in the thin sampler and triangles indicate the accumulated PAH amounts in the thick sampler $\left(N_{S, n g}\right)$. 


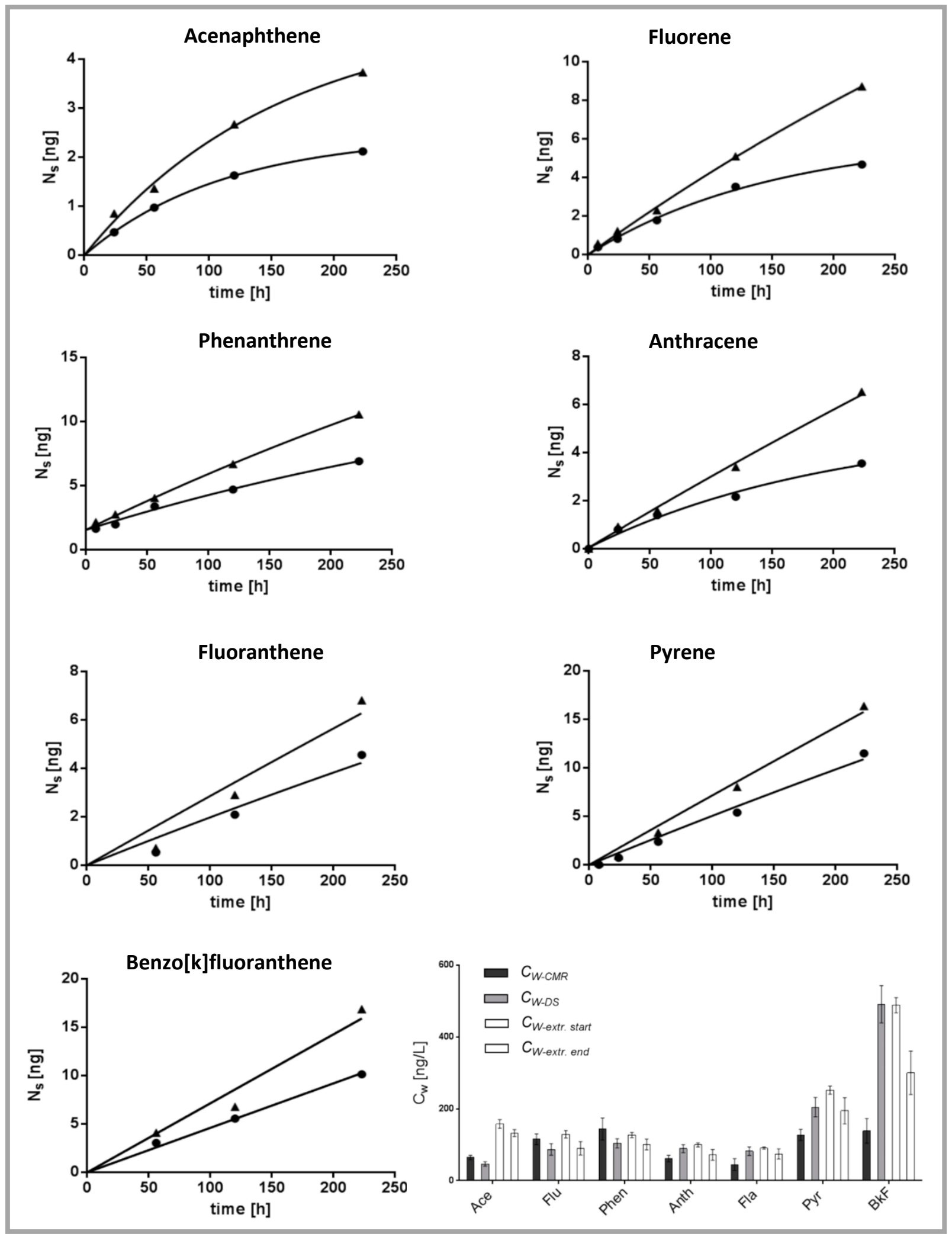

Figure S6. Scatter diagrams: Uptake curves for PAHs in the unstirred system. Circles indicate the accumulated amounts in the thin sampler and triangles indicate the accumulated PAH amounts in the thick sampler $\left(N_{S}, n g\right)$. Benzo[a]pyrene, benzo[ghi]perylene and dibenzo[a,h]anthracene were all below the quantification limits. Column diagram: Dissolved concentrations derived from CMR calibration $\left(C_{W-C M R}, n g / L\right)$, from passive dosing sheet measurements $\left(C_{W-D S}\right)$, as well as from total water extraction $\left(C_{W-e x t r}\right)$ at start and end. 


\section{S7 Experimental data of field study}

Table S7. PRC and CMR sampling rates $\left(R_{S}\right)$ for site 1, 2 and 3.

\begin{tabular}{|c|c|c|c|c|c|c|c|c|c|}
\hline Sampling site & Site 1 & & & Site 2 & & & Site 3 & & \\
\hline Sampling rate & $\begin{array}{l}R_{S-C M R} \\
0.2 / 1\end{array}$ & $\begin{array}{l}R_{S-C M R} \\
0.2 / 3\end{array}$ & $R_{S-P R C}$ & $\begin{array}{l}R_{S-C M R} \\
0.2 / 1\end{array}$ & $\begin{array}{l}R_{S-C M R} \\
0.2 / 3\end{array}$ & $R_{S-P R C}$ & $\begin{array}{l}R_{S-C M R} \\
0.2 / 1\end{array}$ & $\begin{array}{l}R_{S-C M R} \\
0.2 / 3\end{array}$ & $R_{S-P R C}$ \\
\hline & {$[L / d]$} & {$[L / d]$} & {$[L / d]$} & {$[L / d]$} & {$[L / d]$} & {$[\mathrm{L} / \mathrm{d}]$} & {$[L / d]$} & {$[\mathrm{L} / \mathrm{d}]$} & {$[\mathrm{L} / \mathrm{d}]$} \\
\hline Acenaphthylene & $0.26 *$ & $0.22 *$ & 0.13 & $0.18^{*}$ & $0.41 *$ & 0.13 & $0.23^{*}$ & $0.30 *$ & 0.12 \\
\hline Acenaphthene & $0.32^{x}$ & $0.33^{x}$ & 0.13 & $0.18^{*}$ & $0.41 *$ & 0.13 & $0.27^{x}$ & $0.39^{x}$ & 0.12 \\
\hline Fluorene & $0.15^{x}$ & $0.19^{x}$ & 0.12 & $0.13^{x}$ & $0.31^{x}$ & 0.12 & $0.15^{x}$ & $0.29^{x}$ & 0.11 \\
\hline Phenanthrene & $0.22^{x}$ & $0.28^{x}$ & 0.12 & $0.25^{x}$ & $0.86^{x}$ & 0.12 & $0.21^{x}$ & $0.41^{x}$ & 0.11 \\
\hline Anthracene & $0.30^{x}$ & $0.33^{x}$ & 0.12 & $0.14^{x}$ & $0.80^{x}$ & 0.12 & $0.25^{x}$ & $0.53^{x}$ & 0.11 \\
\hline Fluoranthene & $0.23 *$ & $0.19 *$ & 0.11 & $0.16^{*}$ & $0.36^{*}$ & 0.11 & $0.21 *$ & $0.26^{*}$ & 0.10 \\
\hline Pyrene & $0.23 *$ & $0.19 *$ & 0.11 & $0.16^{*}$ & $0.36^{*}$ & 0.11 & $0.21^{*}$ & $0.26^{*}$ & 0.10 \\
\hline Benzo[a]anthracene & $0.22 *$ & $0.18^{*}$ & 0.11 & $0.15^{*}$ & $0.34 *$ & 0.10 & $0.19 *$ & $0.25 *$ & 0.10 \\
\hline Chrysene & $0.22 *$ & $0.18^{*}$ & 0.11 & $0.15^{*}$ & $0.34 *$ & 0.10 & $0.19 *$ & $0.25 *$ & 0.10 \\
\hline Benzo[b]fluoranthene & $0.21 *$ & $0.18^{*}$ & 0.10 & $0.14 *$ & $0.32 *$ & 0.10 & $0.18^{*}$ & $0.24 *$ & 0.09 \\
\hline Benzo[k]fluoranthene & $0.21 *$ & $0.18^{*}$ & 0.10 & $0.14 *$ & $0.32 *$ & 0.10 & $0.18^{*}$ & $0.24 *$ & 0.09 \\
\hline Benzo[a]pyrene & $0.21 *$ & $0.18^{*}$ & 0.10 & $0.14 *$ & $0.32 *$ & 0.10 & $0.18^{*}$ & $0.24 *$ & 0.09 \\
\hline Indeno[1,2,3 cd]pyrene & $0.20^{*}$ & $0.17 *$ & 0.10 & $0.14 *$ & $0.31 *$ & 0.10 & $0.18^{*}$ & $0.23 *$ & 0.09 \\
\hline Dibenzo[a,h]anthracene & $0.20^{*}$ & $0.17^{*}$ & 0.10 & $0.14 *$ & $0.31 *$ & 0.10 & $0.18^{*}$ & $0.23 *$ & 0.09 \\
\hline Benzo[ghi]perylene & $0.20^{*}$ & $0.17^{*}$ & 0.10 & $0.14 *$ & $0.31 *$ & 0.10 & $0.18^{*}$ & $0.23 *$ & 0.09 \\
\hline
\end{tabular}

$R_{S-C M R ~ 0.2 / 1}$ and $R_{S-C M R ~ 0.2 / 3}$ : Sampling rates derived via CMR calibration using thin $(0.2 \mathrm{~mm})$ and intermediate

$(1 \mathrm{~mm})$ as well as thin and thick $(3 \mathrm{~mm})$ samplers

${ }^{x}$ individual sampling rates derived via Equation 2

* modeled sampling rates derived via Equation 3

$R_{S-P R C:}$ Sampling rates derived from dissipation of performance reference compounds (PRC) 


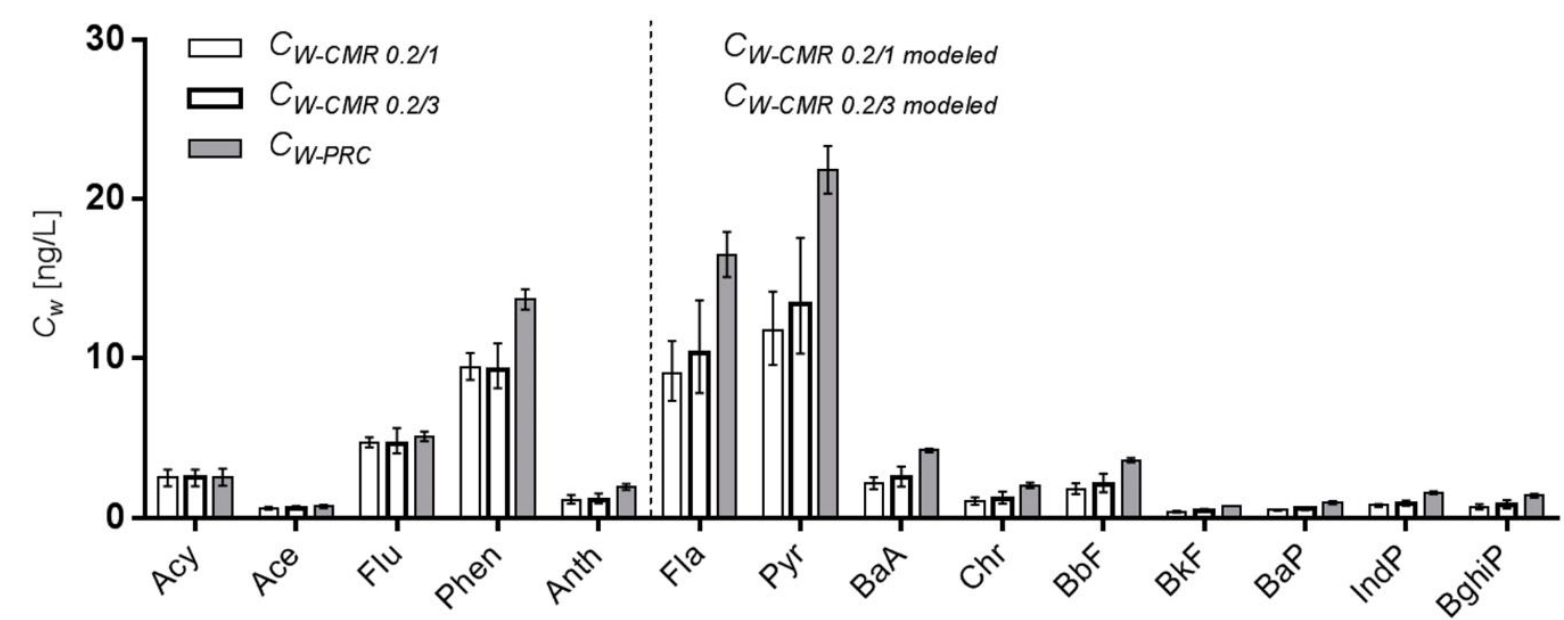

Figure S7. Study results for site 1, after 3 weeks deployment. Comparison of dissolved concentrations determined by the PRC method (grey bars) as well as by the CMR calibration using the amount ratio between the 0.2 and $1 \mathrm{~mm}$ samplers (white bars) and the 0.2 and $3 \mathrm{~mm}$ samplers (white bars, thick border). PAHs to the left were individually determined via Equation 2, PAHs to the right were modeled via Equation 3. Error bars indicate the range in $C_{W}$ calculated using the measurements coming from the replicate samplers (i.e., $n=3$ ).

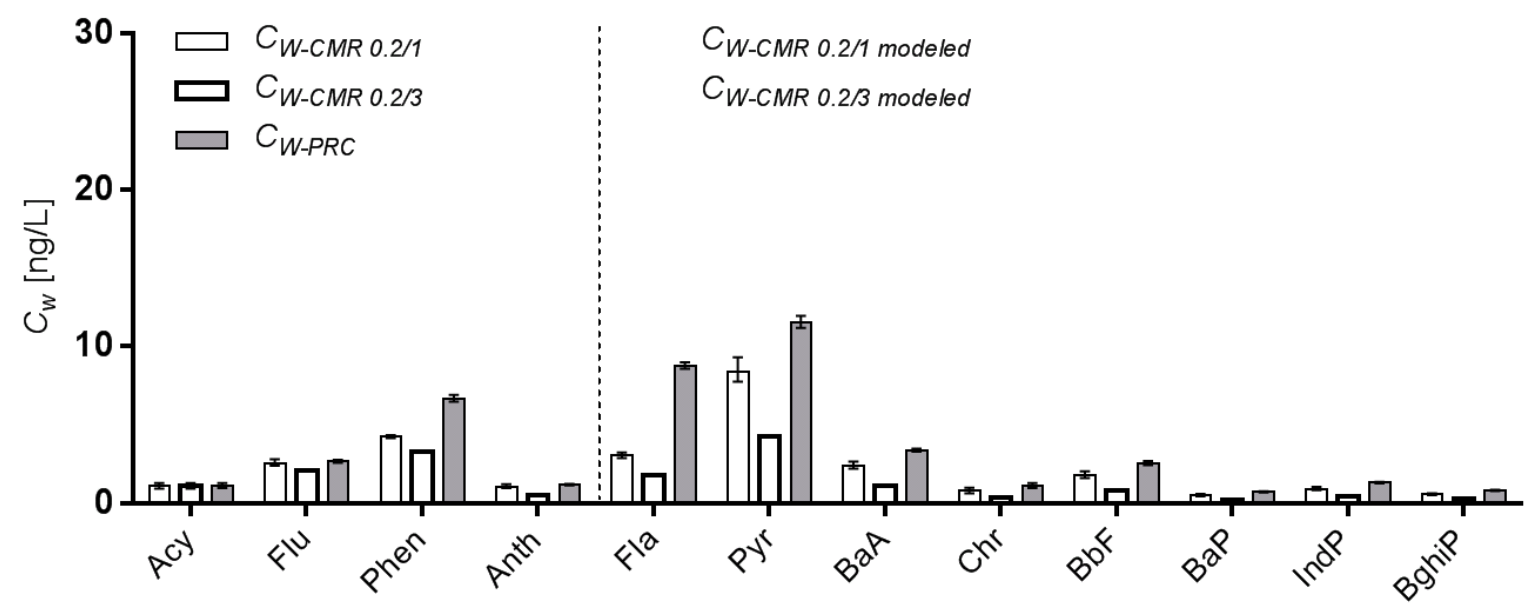

Figure S8. Study results for site 2, after 3 weeks deployment. Comparison of dissolved concentrations determined by the PRC method (grey bars) as well as by the CMR calibration using the amount ratio between the 0.2 and $1 \mathrm{~mm}$ samplers (white bars) and the 0.2 and $3 \mathrm{~mm}$ samplers (white bars, thick border). PAHs to the left were individually determined via Equation 2, PAHs to the right were modeled via Equation 3. Error bars indicate the range in $C_{W}$ calculated using the measurements coming from the replicate samplers (i.e., $n=3$ ). 


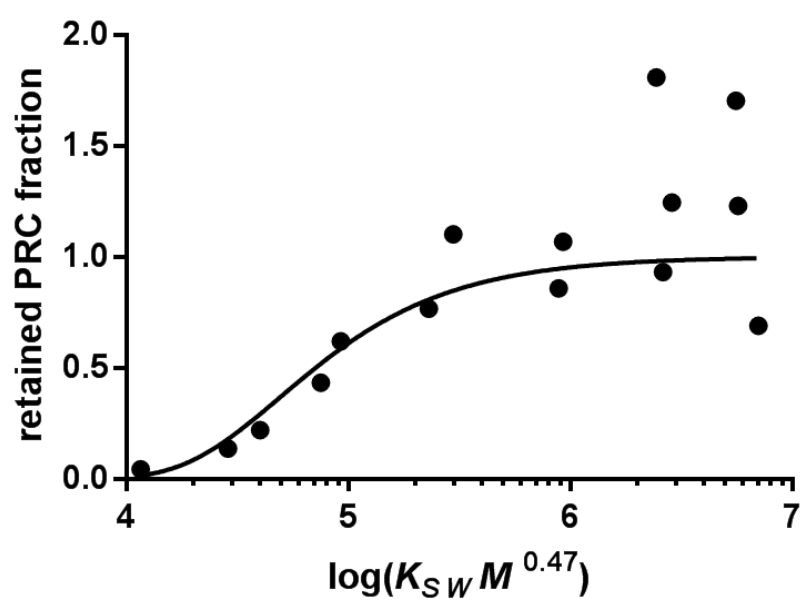

Figure S9. Retained PRC fractions in thin samplers as a function of log $\left(K_{S W} M^{0.47}\right)$ for site 1.

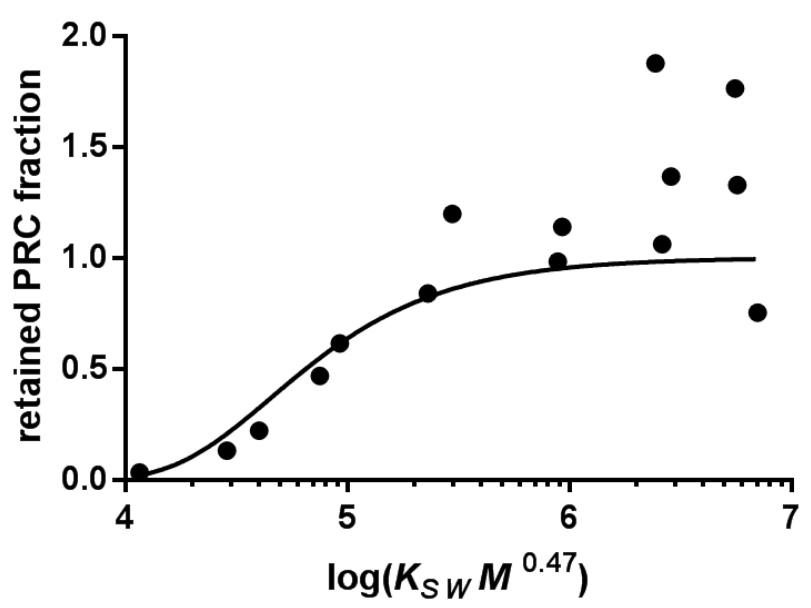

Figure S10. Retained PRC fractions in thin samplers as a function of $\log \left(K_{S W} M^{0.47}\right)$ for site 3.

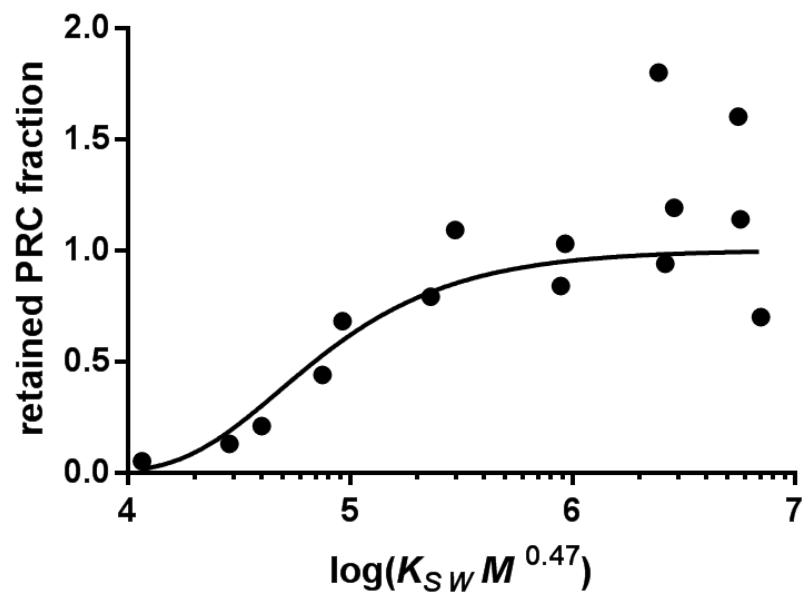

Figure S11. Retained PRC fractions in thin samplers as a function of $\log \left(K_{S W} M^{0.47}\right)$ for site 2. 
1. Smedes, F., SSP silicone-, lipid- and SPMD-water partition coefficients of seventy hydrophobic organic contaminants and evaluation of the water concentration calculator for SPMD. Chemosphere 2019, 223, 748-757.

2. Smedes, F.; Geertsma, R. W.; van der Zande, T.; Booij, K., Polymer-Water Partition Coefficients of Hydrophobic Compounds for Passive Sampling: Application of Cosolvent Models for Validation. Environ. Sci. Technol. 2009, 43, (18), 7047-7054.

3. Fasnacht, M. P.; Blough, N. V., Aqueous photodegradation of polycyclic aromatic hydrocarbons. Environ. Sci. Technol. 2002, 36, (20), 4364-4369.

4. Smedes, F.; Booij, K., Guidelines for Passive Sampling of Hydrophobic Contaminants in Water Using Silicone Rubber Samplers. International Council for the Exploration of the Sea: 2012. 